\title{
Comparison of Short and Prolonged ACT Groups During Cardiopulmonary Bypass about Postoperative Drainage and Blood Transfusion
}

\author{
Berke Özkan, Gökçen Özkan, Öztekin Oto
}

1) Dokuz Eylul University Faculty of Medicine, Department of Thoracic and Cardiovascular Surgery, Izmir / Turkey

\begin{abstract}
Coagulation cascade starts with exsanguination or any contact of blood with an extracorporeal surface ${ }^{(1-5)}$. Since invention of heparin molecule in 1916, it has been an essential application for cardiopulmonary bypass (CPB). Nowadays during CPB we have been using Activated Clotting Time (ACT) test because it results quicker than other laboratory tests to evaluate anticoagulation of heparin. ${ }^{(6-10)}$ During CPB, high anticoagulation levels would result with unexpected high rate non-surgical bleeding. However, lower anticoagulation doses would end up with high rate of thromboembolic events. Both situations can be related with high mortality or morbidity. ${ }^{(13)}$ There have been guidelines about blood conservation in cardiac surgery but clinical management of anticoagulation during CPB is not standardized. ${ }^{(14)}$ In this respect, so far there has not been an ideal universal ACT value. Most clinics sets ACT target as above 400 - 480 seconds during $\mathrm{CPB} .{ }^{(11,12)}$ Over the years most clinics apply $300 \mathrm{IU} / \mathrm{kg}$ dose heparin regimen which has been empirically advanced and universally accepted for CPB to reach target ACT values, but this regimen sometimes can lead to higher ACT values. ${ }^{(13)}$ This situation may cause to more postoperative bleeding, more postoperative blood transfusion and prolonged intensive care staying, although heparin is antagonized with protamine at the end of CPB. In this study we would like to compare retrospectively patients under went open heart surgery whom ACT's during CPB were 400650 seconds with the patients whom ACT's were 650 seconds and higher during CPB.
\end{abstract}

Keywords: Activated clotting time, cardiopulmonary bypass, anticoagulation, postoperative bleeding

Özkan B., Özkan G., Oto Ö. Comparison of Short and Prolonged ACT Groups During Cardiopulmonary Bypass about Postoperative Drainage and Blood Transfusion. EJCM 2018; 06 (3): 111-113. Doi: 10.32596/ejcm.18.00311. 


\section{Introduction}

192 patients underwent CPB over age 18, between October 2014 and May 2014 retrospectively evaluated in our clinic to investigate a comparison of high and low ACT levels patient groups and their postoperative bleeding and related complications.

\section{Materials and Method}

In this study, Hospital operating system and archives were browsed, perfusion notes and intensive care unit notes were scanned, patient weight, operation made, body surface area, CPB time, aortic cross clamp time, gender, age, maximum ACT time during $\mathrm{CPB}$, heparin dose managed, blood transfusion amount, postoperative first day drainage and intensive care duration has recorded. Patients whom anticoagulation had started with $200 \mathrm{IU} / \mathrm{kg}$ heparin dose regimen with ACT range between 400 and 650 seconds during CPB represented as group I and $50 \mathrm{IU} / \mathrm{kg}$ additional heparin dose had been applied when ACT during CPB recorded below 400 seconds. Patients whom anticoagulation had started with $300 \mathrm{IU} / \mathrm{kg}$ heparin dose regimen with ACT range 650 seconds and higher during CPB represented as group II. Those two groups compared for postoperative first day drainage, postoperative blood transfusion amount and intensive care unit staying.

\section{Results}

No significant difference were found between two groups regarding ages $(p=0,126)$, weights $(p=0,526)$, body surface areas ( $p=0,762), C P B$ durations $(p=0,415)$, aortic cross clamp times $(p=0,387)$ are compared. There is statistical relevance between two groups for postoperative first day drainage $(\mathrm{p}=0,000)$, postoperative blood transfusion amount $(\mathrm{p}=0,010)$ and intensive care duration $(p=0,0015)$ which favor for the group whom $\mathrm{ACT}$ range during CPB is $400-650$ seconds.

\section{Discussion}

Blood coagulates with extracorporeal circulation and needs to be anticoagulated. With discovery of heparin molecule blood could be anticoagulated so that cardiopulmonary bypass technology became appli- cable which allowed modern cardiac surgery. Heparin dose management is succeeded with Activated clotting time during Cardiopulmonary bypass in most clinics.

There are studies that shows monitorization and management of anticoagulation with ACT during CPB cause minimum post-operative bleeding and blood transfusion. (15-17) During CPB some studies point that heparin dose and anticoagulation is not proportional but there is an exponential relation between them..$^{(18,19)}$ There is not a universal figure for an optimal ACT time for CBP, but 400-480 seconds of ACT stands as consensus. ${ }^{(20,21)}$

A study shows us most clinics in USA and Canada targets 400-480 seconds of ACT during CPB .(11) Under coagulation during CBP can result with thromboembolic events on the contrary over coagulation can result with non-surgery related bleeding and increased post-operative drainage and need of blood transfusion. During CBP most frequently used method is ACT but there is not a universal ideal ACT level ${ }^{(11,12)}$ even so an empiric $300 \mathrm{IU} / \mathrm{kg}$ dose of heparin to inhibit coagulation during CPB is widely accepted. ${ }^{(21)}$

In a randomized clinical trial with 195 patients who were divided into four groups respectively; 100, 200, 250 and $300 \mathrm{IU} / \mathrm{kg}$ doses of heparin groups by a close perioperative ACT follow-up, ACT was determined to be minimum of 480 seconds, an additional $50 \mathrm{IU} /$ $\mathrm{kg}$ heparin administered if necessary to achieve ACT as maintained higher than 480 seconds. The perioperative heparin dose administered associated with postoperative drainage, which means that patients with lower doses of heparin had less postoperative drainage. ${ }^{(14)}$

In another study of 100 patients who were perioperatively heparinized at a dose of $300 \mathrm{IU} / \mathrm{kg}$ and $145 \mathrm{pa}-$ tients who started heparinization at a dose of $145 \mathrm{IU} / \mathrm{kg}$ with a minimum target of 300 seconds, followed with close ACT monitorization perioperatively and patients applied additional dose of heparin under target ACT. Low dose heparin patients had less blood transfusions and had less postoperative drainage. ${ }^{(16)}$ In this study, we compared two groups of patients ${ }^{(22)}$ whom underwent open heart surgery with CPB and perioperatively close ACT monitored. Group I had anticoagulation started with 200IU/kg heparin dose and additional 50IU/kg 
heparin administered below the target 400 seconds $\mathrm{ACT}$ and perioperative maximum of 650 seconds ACT. Group II had started anticoagulation with $300 \mathrm{IU} / \mathrm{kg}$ dose heparin whom ACT counted above 650 seconds perioperatively during CPB. Between those two groups, there were no significant dif- ference for age, for weight, for aortic cross clamp time, body surface area and CPB time. Patients during CPB with ACT range between 400 and $650 \mathrm{sec}-$ onds favors for less postoperative first day drainage, postoperative blood transfusion and intensive care unit staying.

\section{References}

1. Bigelow WG, Callaghan JC, Hopps JA: General hypothermia for experimental intracardiac surgery. Ann Surg. 132:531 1950

2. Kirklin JW: Open-heart surgery at the Mayo Clinic. The $25^{\text {th }}$ anniversary. Mayo Clin Proc. 55:339 19806990115

3. Boyle EM Jr, Pohlman TH, Johnson MC, Verrier ED: Endothelial cell injury in cardiovascular surgery: the systemic inflammatory response. Ann Thorac Surg. 63:2771997

4. Coronary artery bypass surgery with heparin-coated perfusion circuits and low-dose heparinization John C. Mullen, Michael J. Bentley, BSc (MLS); Elliot T. Gelfand, Arvind Koshal, Dennis L. Modry, Craig R. Guenther, Wai S. Etches, Linda J. Stang, MLT Steven R. Lopushinsky

5. Dunn J, Kirsh MM, Harness J, Carroll M, Straker J, Sloan H: Hemodynamic, metabolic, and hematologic effects of pulsatile cardiopulmonary bypass. J Thorac Cardiovasc Surg

6. Hattersley PG. Activated coagulation time of whole blood. Jama 1966 May 2;196(5):436

7. Hattersley PG. Activated coagulation time as screening test. Jama. 1972 Oct 30;222(5):583-4

8. Hattersley PG. Progress report: the activated coagulation time of whole blood (ACT). Am J Clin Pathol. 1976 Nov;66(5):899-904.

9. Hattersley PG. A semiautomated instrument for the activated coagulation time (ACT). Am J Clin Pathol. 1980 Feb;73(2):293.

10. Reich DL, Zahl K, Perucho MH, Thys DM. An evaluation of two activated clotting time monitors during cardiac surgery. J Clin Monit. 1992;8(1):33-6.

11. Lobato RL, Despotis GJ, Levy JH, Shore LJ, Carlson MO, BennettGuerreroE: Anticoagulation management during cardiopulmonary bypass: a survey of 54 North American institutions. J Thorac Cardiovasc Surg.

12. Anesthesia \& Analgesia: October 2010 - Volume 111 - Issue 4 - p 833-835 doi: 10.1213/ANE.0b013e3181f08a80 Activated Clotting Times, Heparin Responses, and Antithrombin: Have We Been Wrong All These Years? Levy, Jerrold H. MD, FAHA; Sniecinski, Roman M. MD

13. Doty DB, Knot HW, Hoyt JI, Koepke JA. Heparin dose for accurate anticoagulation in cardiac surgery. J Cardiovasc Surg 1979;20: 597-604.

14. Shuhaibar MN, Hargrove M, Millat MH, O'Donnell A, Aherne T: How much heparin do we really need to go on pump?A rethink of current practices: European Journal of Cardio-thoracic Surgery 2004: 947-950.

15. Verska JJ. Control of heparinization by activated clotting time during bypass with improved postoperative hemostasis. Ann Thorac Surg 1977;24:170-3.

16. Hill JD. Dontigny L. de Leval M. et al. A simple method of heparin management during prolonged extracorporeal circulation. Ann Thorac Surg 1974;17:129-34.

17. Babka R, Colby C. E1-Etr A, et al. Monitoring of intra-arterial heparinization and blood 10ss following cardiopuimonary bypass surgery.

18. Bull BS, Huse WM, Brauer FS, et al. Heparin therapy during extracorporeal circulation: II. J THORAC CARDIOVASC SURG 1975;69:685-9.

19. Esposito RA, Culliford AT, Colvin SB, Thomas S J, Lackner H. Spencer FC. Heparin resistance during cardiopulmonary bypass: the role of heparin pretreatment. J THORAC CARDIOVASC SURG 1983;85:346-53.

20. Kouchoukos NT, Blackstone EH, Hanley FL, Kirklin CK: Cardiac Surgery.2012;fourth edition: volüme 1; 105-106.

21. Aki BF, Vargas GM. Neal J, Robillard J, Kelly P. Clinical experience with the activated clotting time for the control of heparin and protamine therapy during cardiopulmonary bypass. J THORAC CARDIOVASC SURG 1980;79:97-102.

22. Reser D., Kolbe M., Pomar JL., Maisano F., Taramasso M. How to make a "Heart Team" a "real" Team to ensure optimal patient care. EJCM 2018; 06 (2): 32-35. Doi: 10.15511/ejcm.18.00232.

Received: 29/05/2018

Accepted: 13/06/2018

Published: 15/09/2018

\section{Disclosure and conflicts of interest:}

The authors declare no conflict of interest.

\section{Disclosure and conflicts of interest:}

The authors declare no conflict of interest.

\section{Corresponding author:}

Berke Özkan

Mail: ozkanberke@gmail.com 